\title{
Imaging of Peripheral Vascular Malformations: Imaging Modalities Mini Review
}

Natalia K Majewska ${ }^{1 *}$, Piotr Stajgis ${ }^{1}$, Mateusz Wykrętowicz ${ }^{1}$, Marek Stajgis ${ }^{1}$, Grzegorz Oszkinis ${ }^{2}$ and Katarzyna Katulska ${ }^{1}$

${ }^{1}$ Department of General Radiology and Neuroradiology, Poznan University of Medical Sciences, Poland

${ }^{2}$ Department of General and Vascular Surgery, Poznan University of Medical Sciences, Poland

\begin{abstract}
Currently the major aim inperipheral vascular malformation (PVM) diagnosis, crucial for subsequent management and treatment, is to identify its hemodynamic characteristics. Other significant features that should be specified by a radiologist is the exact location of the anomaly, its size and morphology. Until recently the diagnostic methods available for comprehensive evaluation of malformations have been rather limited. Moreover, they were often associated with the necessity of exposing the patient to $\mathrm{X}$-ray radiation and with invasive procedures, asfor example in angiography. The development of imaging techniques used in the diagnosis of vascular abnormalities in recent years, especially magnetic resonance imaging (MRI), has largely contributed to improved diagnostic value of the tests. In this article we review the currently available imaging modalities with particular consideration of magnetic resonance imaging and its capability to distinguish between high-flow and low-flow malformations.
\end{abstract}

Keywords: Vascular malformation; Imaging; Magnetic resonance; Low-flow and high-flow malformations

\section{Introduction}

Peripheral vascular malformations (PVM) are a heterogeneous group of abnormalities that may present significant diagnostic and therapeutic challenge. The frequency of PVM occurrence in general population is approx. $0.8-1 \%$ [1] and their most common locations are in the head and neck (approx. $40 \%$ of cases), limbs (40\%) and trunk (20\%) [2]. PVMs manifest in a wide spectrum of non-specific symptoms depending on their location and size, ranging from small subcutaneous lesions to limb deformation when the malformation affects growth cartilage and to potentially life-threatening malformations that cause hemodynamic dysfunctions leading to heart failure [3].

\section{Classification}

The first classification of vascular anomalies based on their biological and histological characteristics and natural history was presented in 1982 by Mulliken and Glowacki who divided the anomalies into two major categories: hemangiomas and vascular malformations [4]. In 1993 Jackson et al. presented their classification of vascular malformations based on the lesions' radiological characteristics and flow dynamics, distinguishing between high-flow and low-flow malformations [5]. The aim of such classification was to provide a communication platform for both radiologists and surgeons and most importantly to allow dedicated treatment planning for individual lesions. The division into high-flow and low-flow malformations was made using angiography. The researchers defined high-flow malformations as those where arterial and venous phases appear in one angiographic image and consist of multiple and twisted arterial and venous vessels with a visible feeding artery, a nidus and/or shunting (Figure 1).

A nidus is a tangle of abnormal, small and twisted vessels forming the transition between the feeding arteries and the draining veins, bypassing a capillary bed. Due to a big pressure difference within the nidus some of the vessels form direct connections whose hemodynamic characteristics correspond to arteriovenous shunts.

In 1996 both classifications were adapted and expanded by the International Study of Vascular Anomalies (ISSVA). The update made in 2014 represents currently the conclusive, widely used classification (Table 1) [6]. It divides the malformations considering their hemodynamic and morphological characteristics respectively into high-flow and low-flow malformations and then further narrows down the division distinguishing between simple and complex malformations. All malformations with the arterial component in their morphology are classified as high-flow malformations.

\section{Diagnostics}

For each disease the key components of diagnosis are a detailed physical examination and patient interview. Still, in case of PVM they are not sufficient for a physician to determine the size, location and

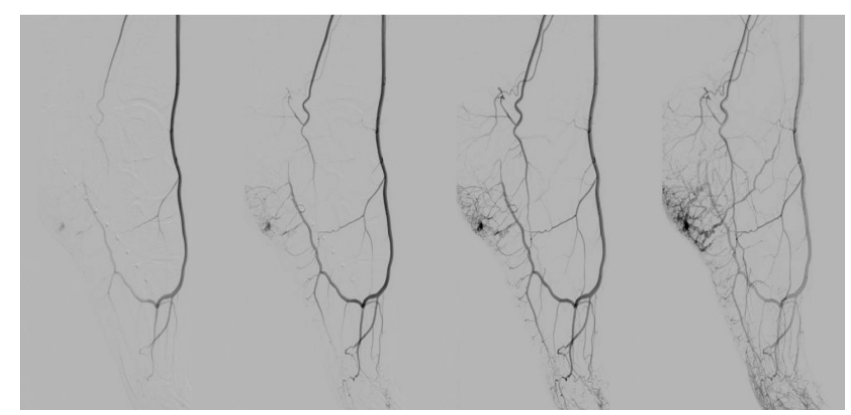

Figure 1: Digital subtraction angiography of high-flow vascular malformation of the foot. In all expositions there seen a nidus of the malformation, which is located in the heel. In two lasts expositions there are seen both arterial and venous phase and nidus.

*Corresponding author: Natalia K Majewska, Department of General Radiology and Neuroradiology, Poznan University of Medical Sciences, Poland, Tel: +48505074230; E-mail: nkmajewska@gmail.com

Received September 14, 2017; Accepted October 11, 2017; Published October 17, 2017

Citation: Majewska NK, Stajgis P, Wykrętowicz M, Stajgis M, Oszkinis G, et al. (2017) Imaging of Peripheral Vascular Malformations: Imaging Modalities Min Review. J Vasc Med Surg 5: 340. doi: 10.4172/2329-6925.1000340

Copyright: (c) 2017 Majewska NK, et al. This is an open-access article distributed under the terms of the Creative Commons Attribution License, which permits unrestricted use, distribution, and reproduction in any medium, provided the original author and source are credited. 


\begin{tabular}{|l|l|l|}
\hline \multirow{2}{*}{ Flow } & Vascular malformation & \\
\cline { 2 - 3 } & Simple & Combined \\
\hline \multirow{2}{*}{ High-flow } & Capillary malformations & CVM, CLM \\
\hline & Lymphatic malformations & LVM, CLVM \\
\hline & Venous malformations & \\
\hline & Arteriovenous malformation & CAVM, CLAVM \\
\hline & Arteriovenous fistula & \\
\hline
\end{tabular}

Table 1: International Study of Vascular Anomalies classification of vascular malformation.

\begin{tabular}{|c|c|c|}
\hline $\begin{array}{l}\text { Vascular } \\
\text { malformation }\end{array}$ & B-Mode & Doppler \\
\hline \multicolumn{3}{|l|}{ Low-flow } \\
\hline \multirow[t]{3}{*}{ Venous } & Echogenic mass & \multirow{3}{*}{$\begin{array}{l}\text { Monophasic or no flow } \\
\text { pattern }\end{array}$} \\
\hline & Phleboliths & \\
\hline & $\begin{array}{l}\text { Often multispatial and } \\
\text { compressible }\end{array}$ & \\
\hline \multirow[t]{2}{*}{ Lymphatic } & Variable multicystic & \multirow[t]{2}{*}{ No flow, except in septa } \\
\hline & $\begin{array}{l}\text { Multispatial masses with or } \\
\text { without fluid and derbis level }\end{array}$ & \\
\hline \multicolumn{3}{|l|}{ High-flow } \\
\hline \multirow{2}{*}{$\begin{array}{l}\text { Arteriovenous } \\
\text { malformation and } \\
\text { fistulas }\end{array}$} & $\begin{array}{l}\text { Cluster of vessels with no } \\
\text { intervening }\end{array}$ & $\begin{array}{l}\text { Arterial and venous signals } \\
\text { from vessels in the }\end{array}$ \\
\hline & Well-defined mass & $\begin{array}{l}\text { Lesions with arterialization } \\
\text { of venous structures }\end{array}$ \\
\hline
\end{tabular}

Table 2: B-Mode and Doppler ultrasound imaging features of common vascular malformations.

type of the anomaly. Thus, diagnostic imaging is essential in diagnosing patients suffering from PVM. Radiological image allows to identify precisely the location of the anomaly, its size, the extent of the affected tissues and the type of the malformation. Identification of the flow type is crucial. It determines further management and treatment of the condition. Currently, low-flow malformations are usually treated with the use of percutaneous sclerotherapy and high-flow malformations with transarterial embolization or with both methods simultaneously [7-10]. Imaging modalities as well as their role and adequacy in PVM diagnosis are reviewed below.

\section{Ultrasound examination}

Doppler ultrasound examination is the basic, widely available diagnostic tool. It is usually the first imaging examination for patients with a malformation presenting as a subcutaneous lesion. The exam allows to evaluate the characteristics and the flow velocity within the malformation in real time. Percutaneous sclerotherapy of PVM is often performed with the assistance of ultrasound guidance. Ultrasound is also extremely useful to monitor patients who underwent therapeutic procedures treating PVM. The disadvantages of the ultrasound are its lack of precision in evaluation of anomalies located deep in the tissues or in immediate vicinity to the bone and its dependency on the experience of the person performing the examination $[10,11]$. The characteristic features of the high-flow and low-flow malformations are presented in Table 2 [12]. In the currently available literature there is no data on the sensitivity and specificity of the ultrasound technique in differentiating between vascular malformations.

\section{Radiography}

Conventional radiography plays a limited role in PVM diagnostics. It does not allow to classify the anomaly. Still, radiographs showing anomalies in the bones such as erosions, sclerotization, periosteal reaction and pathologic fractures suggest that the malformation affects

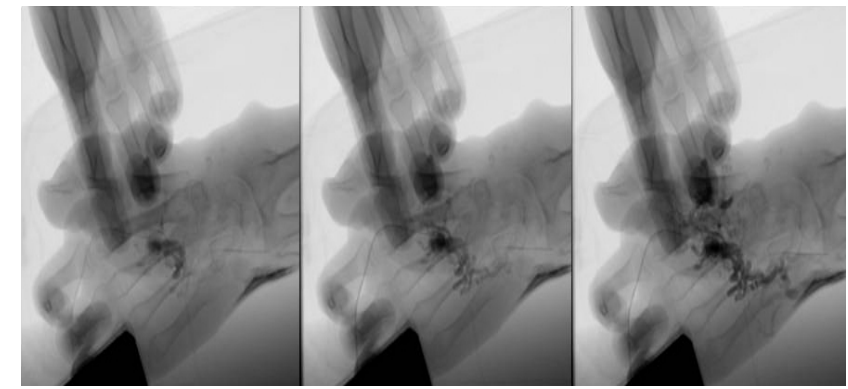

Figure 2: Angiography of vascular malformation of the hand through direct percutaneous nidus puncture.

the bone tissue. The presence of calcifications (phleboliths) in soft tissue projection points to a low-flow venous malformation [10].

\section{Arteriography and phlebography}

Arteriography and phlebography are imaging methods directly preceding a potential medical procedure. Although the methods are invasive and expose the patient to X-ray radiation, at the same time they offer adequate assessment of the size of the nidus as well as the feeding and draining vessels, in particular through percutaneous nidus puncture [13] (Figure 2).

\section{Computer tomography}

With multi-slice computer tomography (CT) with intravenous contrast administration one can perform a fast evaluation of the malformation and the potential complications that may occur. High spatial resolution makes it possible to precisely assess the location and configuration of the feeding and draining vessels. The disadvantage of CT is a significant dose of ionizing radiation. Because of that the number of acquisitions in the dynamic test is limited, which makes the evaluation of blood flow dynamics difficult.

\section{Magnetic resonance}

Magnetic resonance imaging (MRI) is the most valuable imaging method when diagnosing vascular malformations. MRI allows to identify precisely the location of the anomaly and the extent of the affected tissues. Also, dynamic MRI is the only method that allows to classify the malformation as low- or high-flow one with a high level of sensitivity and specificity.

Currently most of the available tests used to diagnose vascular malformations have been performed with $1.5 \mathrm{~T}$ systems as they are more accessible. There have been recently first publications reviewing the use of 3.0T system [14]. Still, there are no data offering a direct comparison between the two systems' sensitivity and specificityin differentiating vascular malformations.

Most of the diagnostic protocols consist of the following sequences: spin echo (SE) or fast spin echo(FSE) T1-weighted, T2-weighted with fat saturation or short tau inversion recovery (STIR), T2-weighted GRE, volumetric interpolated breath-hold examination (VIBE) and dynamic MR angiography (DCE-MRA) [15]. T1-weighted sequences are used to identify the location and anatomic relationship to adjacent structures. With T2-weighted sequence and STIR it is possible to determine the extent of the malformation, demonstrate more precisely the lesion within the surrounding fat tissue and conduct preliminary assessment of the flow dynamics. DCE-MRA e.g., time-resolved angiography with 
Citation: Majewska NK, Stajgis P, Wykrętowicz M, Stajgis M, Oszkinis G, et al. (2017) Imaging of Peripheral Vascular Malformations: Imaging Modalities Mini Review. J Vasc Med Surg 5: 340. doi: 10.4172/2329-6925.1000340

Page 3 of 5

interleaved stochastic trajectories (TWIST), enhanced with gadolinium contrast material is the essential sequence which make it possible to conduct a detailed evaluation of the architecture and hemodynamic properties of the malformation. VIBE and T1-weighted sequences are usually repeated after TWIST sequence (after contrast injection) as the delayed venous phase. This is used to examine the very-low-flow malformations andthe extent of its drainage in the venous system $[15,16]$. The above described sequences are also applied in checkup tests after medical procedures e.g., sclerotherapy or embolization.

Primary characteristics of individual types of vascular malformations revealed in MR imaging are presented in Table 3 [15].

Owing to a high spatial and temporal resolution of up to $2 \mathrm{~s}$ and the possibility to acquire images in many phases (early arterial and arterial phase, intermediate and venous) the TWIST sequence permits to identify the time between the onset of arterial phase enhancement (of the artery that is not affected by the malformation) and the onset of the lesion enhancement $\left(\mathrm{t}_{\text {onset }}\right)$ and the maximum enhancement time $\left(\mathrm{t}_{\max }\right)$ and to determine the lesion enhancement curve. Recent research made on small groups of patients demonstrated that these properties permit to classify the malformation as low-flow or high-flow. In their research Kociemba et al. [16] defined $t_{\text {onset }} \leq 4,1$ s and $t_{\text {max }} \leq 27 \mathrm{~s}$ as the cut-off points for high-flow malformations characterized by sensitivity and specificity reaching respectively approx. $100 \%$ and $57 \%$ for $t$ $(\mathrm{AUC}=0.89)$ and $94 \%$ and $100 \%$ for $\mathrm{t}_{\max }(\mathrm{AUC}=0.99)$ [16]. Similar values of cut-off points for these variables were obtained by Ohgiya et al. [17] $\mathrm{t}_{\text {onset }} \leq 5 \mathrm{~s}$ and $\mathrm{t}_{\max } \leq 30$ s for which sensitivity reached $100 \%$ for both and specificity reached $60 \%$ for $t_{\text {onset }}$ and $100 \%$ for $t_{\text {max }}$ [17]. Additionally, there is another variable proposed by Hammer et al. [14] determined on the basis of the enhancement curve and useful in differentiating the flow type within the malformation, namely the maximum percentage increase in signal intensity from baseline within the lesion ( signal $_{\max }$ ) (Figures 3 and 4 ). It is calculated as follows:

$\mathrm{Signal}_{\max } \frac{\text { maximum signal intensity after enhancement }- \text { signal intensity before enhancement }}{\text { signal intensitybefore enhancement }} \times 100$

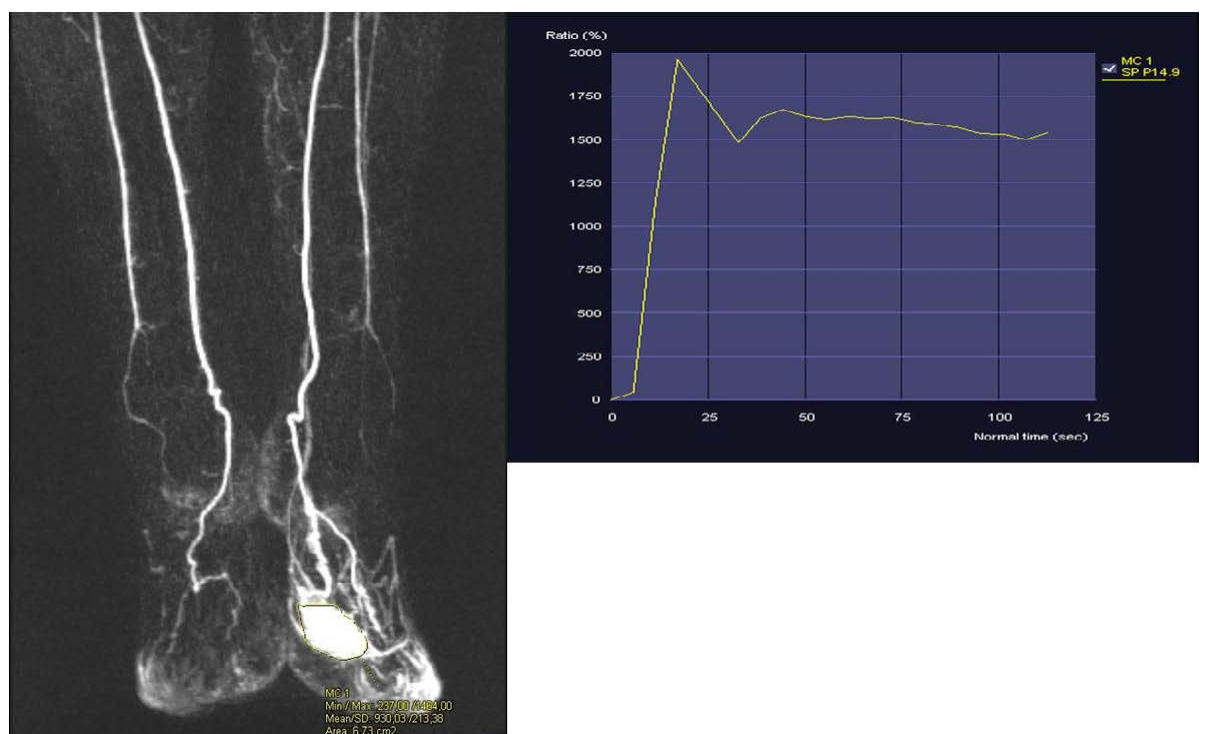

Figure 3: Dynamic MR angiography of high-flow malformation of the forefoot and its enhancement curve. Peak of the curve appear shortly after intravenous administration of contrast agent.

\begin{tabular}{|cl|}
\hline Low-flow malformation \\
\hline Venous malformation \\
$-\quad$ Septated lobulated mass without mass effect \\
- & Phleboliths (low SI), fluid-fluid levels, low SI on T1WI, high SI on T2WI \\
- & No flow voids on SE images \\
- & Infiltrates tissue planes and possible surrounding oedema \\
- & No arterial or early venous enhancement \\
- & Slow gradual enhancement and diffuse enhancement on delayed images \\
- & with some late enhancement ( $\geq 5$ s) \\
- & Normal afferent arteries \\
\hline & imaging \\
\hline Lymphatic & \\
- & Septated lobulated mass with some fluid-fluid levels \\
- & Can see infiltration of tissue planes \\
- & Low SI on T1WI, high SI on T2WI \\
- & No flow voids on SE images \\
- & Rim and septal enhancement $n$ \\
- & No significant or slight diffuse enhancement \\
\hline Capilary & \\
- & Skin-thickness lesion \\
\hline
\end{tabular}

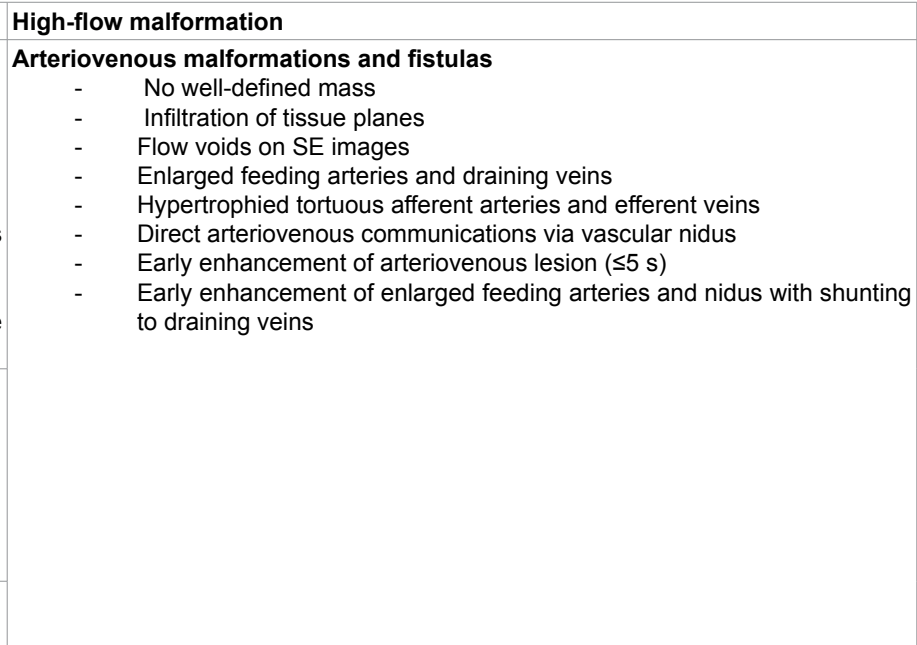

SE: spin echo; SI: signal intensity; T1WI: T1 weighted imaging; T2WI: T2 weighted imaging

Table 3: MR Imaging Features of Vascular Malformation [14]. 
Citation: Majewska NK, Stajgis P, Wykrętowicz M, Stajgis M, Oszkinis G, et al. (2017) Imaging of Peripheral Vascular Malformations: Imaging Modalities Mini Review. J Vasc Med Surg 5: 340. doi: 10.4172/2329-6925.1000340

Page 4 of 5

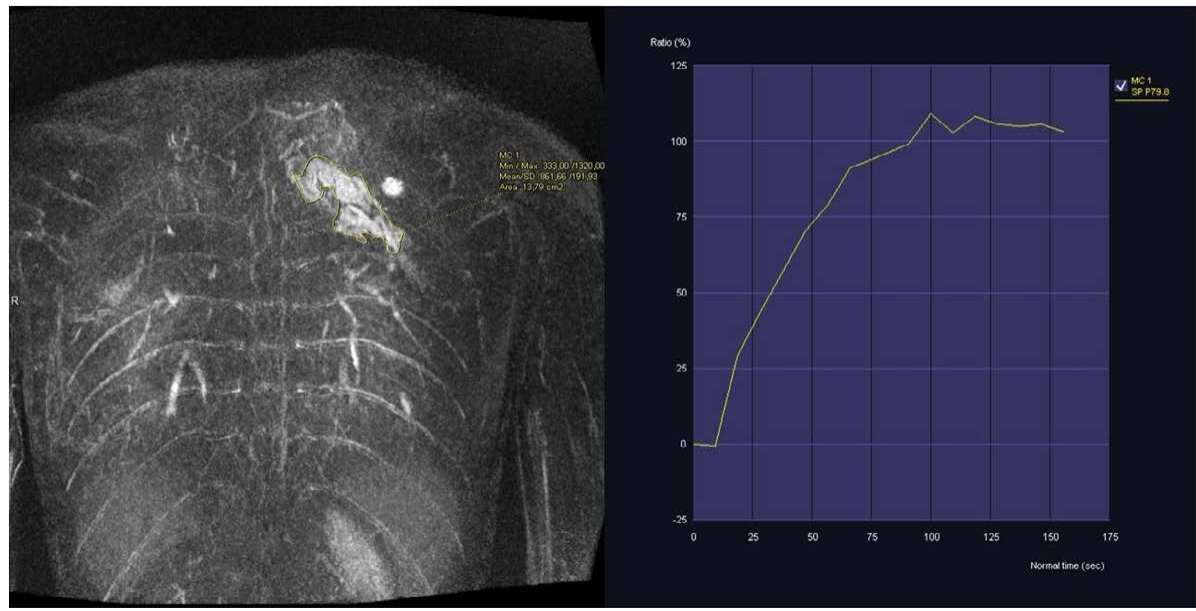

Figure 4: Dynamic MR angiography of low-flow malformation of the upper torso and its enhancement curve. After intravenous administration of contrast agent, the curve rise slowly to its maximum.

The study proved the effectiveness of the variable in differentiating between sub-types of low-flow malformations either containing hypodynamic AVF or not. The calculated value of the cut-off point was $\geq 419 \%$ for VM containing hypodynamic AVF. After setting the ROC curve, AUC was 0.85 [14].

Due to the risk of potential occurrence of nephrogenic fibrosis after administration of gadolinium contrast in patients with kidney failure it is currently attempted to develop and use angiographic sequences without intravenous contrast, such as time of flight (TOF) andphasecontrast (PC). These techniques are used to evaluate peripheral blood vessels but they have certain constraints. Slowing down the flow and saturating the signal in a plane that is not transverse may be a problem for acquisition of diagnostic images in TOF sequence. Another challenge is the selection of appropriate velocity encoding in PC sequence. Moreover, these sequences require a long acquisition time $[18,19]$.

Alternative angiographic techniques are being developed, such as electrocardiographically gated three-dimensional (3D) partial Fourier FSE which is based on subtraction of images in systolic and diastolic phase [20]. The technique has its downsides such as artifacts (blurring) and low sensitivity as regards low-flow vessels in distal parts of the limbs.

Another alternative method is arterial spin labeling (ASL) combined with partial-Fourier FSE. This technique allows to eliminate the signal from the background and better visualize small vessels. ASL provides data about the blood flow, whereas partial-Fourier FSE shows the lesion's morphology [18].

\section{Conclusion}

To sum up, vascular malformations may be visualized with the use of various imaging modalities. Still, MRI is the method of choice as the most effective in delivering significant data about the lesion. At the same time, MRI is quite non-invasive and the burden on the patient is small, limited to intravenous contrast administration. In particular DCE-MRA yields essential information on the type of the malformation and allows for further therapy planning and outcome monitoring.

\section{References}

1. Tasnádi G (1993) Epidemiology and etiology of congenital vascular malformations. SeminVasc Surg 6: 200-203

2. Dubois J, Soulez G, Oliva VL, Berthiaume MJ, Lapierre C, et al. (2001) Softtissue venous malformations in adult patients: imaging and therapeutic issues. Radio Graphics 21: 1519-1531.

3. Ernemann U, Kramer U, Miller S, Bisdas S, Rebmann H, et al. (2010) Current concepts in the classification, diagnosis and treatment of vascular anomalies. Eur J Radiol 75: 2-11.

4. Mulliken JB, Glowacki J (1982) Hemangiomas and vascular malformations in infants and children: a classification based on endothelial characteristics. Plast Reconstr Surg 69: 412-422.

5. Jackson IT, Carreño R, Potparic Z, Hussain K (1993) Hemangiomas vascular malformations, and lymphovenous malformations: classification and methods of treatment. Plast Reconstr Surg 91:1216-1230.

6. ISSVA Classification of Vascular Anomalies (C2014 International Society for the Study of Vascular Anomalies Available at "issva.org/classification" Accessed 27.03.2017

7. Moukaddam H, Pollak J, Haims AH (2009) MRI characteristics and classification of peripheral vascular malformations and tumors. Skeletal Radiol 38: 535-547.

8. Fayad LM, Hazirolan T, Bluemke D, Mitchell S (2006) Vascular malformations in the extremities: emphasis on MR imaging features that guide treatment options. Skeletal Radiol 35:127-137.

9. Ernemann U, Kramer U, Miller S, Bisdas S, Rebmann H, et al. (2010) Current concepts in the classification, diagnosis and treatment of vascular anomalies. Eur J Radiol 75: 2-11.

10. Hyodoh H, Hori M, Akiba H, Tamakawa M, Hyodoh K, et al. (2005) Peripheral vascular malformations imaging, treatment approaches, and therapeutic issues. Radiographics 25: S159-S171.

11. Gruber H, Peer S (2009) Ultrasound diagnosis of soft tissue vascular malformations and tumours. Curr Med Imaging Rev 5: 55-61.

12. Lowe LH, Marchant TC, Rivard DC, Scherbel AJ (2012) Vascular malformations: classification and terminology the radiologist needs to know. Semin Roentgeno 47: 106-17.

13. Inoue Y, Ohtake T, Wakita S, Yoshikawa K, Kaji N, et al. (1997) Flow characteristics of soft-tissue vascular anomalies evaluated by direct puncture scintigraphy. Eur J Nucl Med 24: 505-510.

14. Hammer S, Uller W, Manger F, Fellner C, Zeman F, et al. (2017) Timeresolved magnetic resonance angiography (MRA) at 3.0 Tesla for evaluation of hemodynamic characteristics of vascular malformations: description of distinct subgroups. Eur Radiol 27: 296-305.

15. Flors L, Leiva-Salinas C, Maged IM, Norton PT, Matsumoto AH, et al. (2011) MR imaging of soft-tissue vascular malformations: diagnosis, classification, and therapy follow-up. Radiographics 31: 1321-1340. 
Citation: Majewska NK, Stajgis P, Wykrętowicz M, Stajgis M, Oszkinis G, et al. (2017) Imaging of Peripheral Vascular Malformations: Imaging Modalities Mini Review. J Vasc Med Surg 5: 340. doi: 10.4172/2329-6925.1000340

Page 5 of 5

16. Kociemba A, Karmelita-Katulska K, Stajgis M, Oszkinis G, Pyda M (2016) Distinguishing high-flow from low-flow vascular malformations using maximum intensity projection images in dynamic magnetic resonance angiographycomparison to other MR-based techniques. Acta Radiol 57: 565-571.

17. Ohgiya Y, Hashimoto T, Gokan T, Watanabe S, Kuroda M, et al. (2005) Dynamic MRI for distinguishing high-flow from low-flow peripheral vascular malformations. AJR Am J Roentgenol. 185:1131-1137.
18. Miyazaki M, Lee VS (2008) Nonenhanced MR Angiography. Radiology 248: 20-43.

19. Hesselink JR (2014) MR Angiography: CNS applications. UCSD neuroradiology teaching file database.

20. Klasen J, Blondin D, Schmitt P, Bi X, Sansone R, et al. (2012) Nonenhanced ECG-gated quiescent-interval single-shot MRA (QISS MRA) of the lower extremities: comparison with contrast-enhanced MRA. Clin Radiol 67: 441-446. 